\section{ARS Tech}

Authors retain copyright

\section{Applied Research and Smart Technology}

Journal homepage: www.journals2.ums.ac.id/index.php/arstech

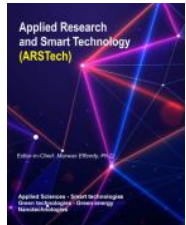

ISSN 2722-9645

Research Article

\title{
Degradation of distillery spent wash using monopolar parallel and monopolar series electrocoagulation process
}

\author{
Sukanya Pujari ${ }^{1}$, Manoj Wagh ${ }^{2,}$, Shila Dare ${ }^{3}$ \\ ${ }^{1}$ Department of Civil Engineering, Basaveshwer Engineering College, India. \\ ${ }^{2}$ Department of Civil Engineering, Dr. Vithalrao Vikhe Patil College of Engineering Ahmednagar, Maharashtra, India \\ ${ }^{3}$ Department of Computer Engineering, Shri Chhatrapati College of Engineering Ahmednagar, Maharashtra, India. \\ ${ }^{*}$ Corresponding author: profmpwagh@gmail.com
}

Permalink (DOI): $\underline{\text { https://doi.org/10.23917/arstech.v2i1.306 }}$

\section{ARTICLE INFO}

\section{Article history:}

Received 23 April 2021

Revised 9 May 2021

Accepted 6 June 2021

Available online 19 June 2021

Published regularly 30 June 2021

\section{Keywords:}

Aluminium foil

Chemical oxygen demand

Distillery spent wash

Electrocoagulation

Novel electrodes

\section{ABSTRACT}

\begin{abstract}
In waste treatment and water management issues, electrocoagulation (EC) is the most cost-effective and environmentally friendly option. In the study, EC treatment of distillery spent wash was carried out using new electrodes packed with aluminium foil scraps. These metal scraps were packed in a mesh to function as anode and cathode electrodes. Electrochemical treatment was carried out for 150 minutes, and samples were analysed regularly to determine the colour and chemical oxygen demand (COD). The impacts of operating parameters such as $\mathrm{pH}$, applied current, electrolysis time, agitation speed, and electrode distance on colour and COD removal were investigated. The EC processes were realised in monopolar parallel (MP-P) and monopolar series (MP-S). The MP-S connection measured the potential difference between the amplified pair of electrodes, whereas the output signals in the MP-P connection were formed by several input electrodes, resulting in a high removal rate. The results indicated that the MP-P relationships enhance the COD removal rate by 4.16 to $8.06 \%$. An optimum chemical oxygen demand degradation is $77.29 \%$ at $\mathrm{pH} 3$, and decolourisation is $76.55 \%$ at $\mathrm{pH} 8.3$. TDS is reduced to a maximum of $58.32 \%$, while sulfate and chloride are reduced to 64.72 and $20.44 \%$, respectively.
\end{abstract}

\section{INTRODUCTION}

Distillery spent wash (DSW) is highly acidic, cumbersome, and toxic, having very high biochemical oxygen demand (BOD), high chemical oxygen demand
(COD), high suspended solids, toxic metals, and heavy metals. It also has high organic and inorganic components, recalcitrant, high total dissolved solids (TDS), sulphate, phosphate, complex, and intensive unwanted residue $[1,2]$. DSW could not be degraded by a single method, 
and it required more than one process to minimise the parameters of the distillery spent wash to dispose of on the ground $[3,4]$ safely. If mixed with groundwater, distillery wastewater may contaminate the water sources, as DSW is highly polluted and can pollute $1000 \mathrm{ml}$ of water with a single drop of distillery spent wash.

Disposing of high-total-dissolved-solids distillery effluent can negatively affect groundwater and the surrounding area of distillery industries. A wash is left to water without treatment when the distillery is spent. It has a high biological oxygen demand, which lowers dissolved oxygen levels in the water, affecting fish reproduction and aquatic plant growth. Existing treatment technologies to reduce the environment's organic load are physicochemical processes such as adsorption, oxidation processes, coagulation and flocculation, membrane treatment, evaporation and combustion, radiation technology, ultrasound technology, and catalytic thermolysis [5-7].

Other treatments based on biological methods are anaerobic systems, anaerobic lagoons, conventional anaerobic systems, anaerobic batch reactors, anaerobic fixed film reactors, up-flow anaerobic sludge blanket (UASB) reactors, anaerobic fluidised bed reactors, aerobic systems, activated sludge process (ASP), bio composting process, phytoremediation cyanobacterial, and algal systems, fungal systems, bacterial systems, membrane bioreactors (MBR) [8-10]. In addition, the yeast sludge from the distilleries, which contains very high suspended solids and BOD and is rich in proteins, carbohydrates, and vitamins, may be treated separately for by-product recovery. But in practice, it is mixed and discharged along with the spent wash, thereby increasing the pollution load of the plant effluent.

A two-stage biological treatment method consisting of an anaerobic treatment followed by anaerobic treatment of the waste has been widely accepted as the only treatment method for rubbish from the distilleries. Both closed anaerobic digestion and open anaerobic lagoons have been tried for anaerobic treatment. Although various treatment options are available for the distillery spent wash, electrocoagulation is a low-cost process, and an efficient method for distillery spent wash involves electrochemical production of destabilising agents that bring about charge neutralisation for pollutant removal $[11,12]$.

The electrochemically generated ion acts as in situ coagulants by associating with the pollutants to form largesize flocs/metal hydroxides and, after that, could be disinterested by straightening out and floatation. Hence, an effort was made to treat distillery spent wash by electrocoagulation technique in the present study using aluminium electrodes packed with aluminium foil scraps as electrode materials connected as a monopolar system. Electrocoagulation uses an electric current to create a coagulant in real-time in wastewater by sacrificing the electrodes. Electrocoagulation uses direct or alternate current to generate sacrificial electrode (anode electrode) ions, which are used to remove unwanted impurities through chemical reactions and precipitation or by causing colloidal materials to be combined and removed by electrolytic flotation.

DSW could be treated with electrocoagulation (EC). For most of the twentieth century, EC treatment technologies were standard, with periodic resurgences in popularity. Because of its high initial cost and competition with other chemical treatment technology, the EC process was phased out of use before 20 years. With the advancement of electrochemical methods and tightening environmental regulations on effluent, it began to regain significance in the twenty-first century. The relative reduction in exploitation and principal costs also contributes to this new EC ascension. The EC can be the most cost-effective and environmentally friendly option for effluent treatment and other water management issues. In the present paper, monopolar parallel and monopolar series electrocoagulation was implemented to degrade the parameters of cumbersome, recalcitrant, highly toxic distillery spent wash.

\section{MATERIALS AND METHODS}

Distillery wastewater sample collected from $\mathrm{M} / \mathrm{s}$. Siddapur distillery industry Siddapur, Taluka Jamkhandi, district Bagalkot, Karnataka. A random selection method was used to manage the distillery wastewater samples. Samples were collected at three different sessions in the morning, afternoon, and evening. A representative composite sample with a volume of two litres was taken from these for further analysis. Samples were collected in polythene bottles that were thoroughly washed with distilled water before being used. A thermometer was used to check and record the initial temperature at the time of wastewater collection. It was also discovered in the range of 37 to $40^{\circ} \mathrm{C}$ to avoid temperature and light changes. Direct sunlight exposure was avoided for the samples.

\subsection{Materials and sample preparation}

To determine the chemical parameters of the distillery spent wash following chemicals were used as Potassium dichromate solution $(0.25 \mathrm{~N})$, Ferrous Ammonium sulphate solution $(0.1 \mathrm{~N})$, Silver sulphate, Mercuric sulphate, Standard silver nitrate solution $(0.0141 \mathrm{~N})$, Standard Chlorine solution $(0.0141 \mathrm{~N})$ and Potassium Chromate indicator ( $\mathrm{K} 2 \mathrm{Cr} 2 \mathrm{O} 7)$. All the analytical reagent (AR) grade chemicals were purchased locally from MIDC, Bagalkot, Karnataka. 
Following equipment was used in the experiments, such as Magnetic Stirrer REMI (Model, 2MLB), UV/Vis Spectrophotometer Double beam, Czerny Turner monochromator, EIE Instrumentation COD Hot Plates with specification VIPL/EIE 5101 (F) 15 tubes, analogue voltage, current meter with DC power supply, and aluminium electrodes having composition $\mathrm{Al} 97.596 \%, \mathrm{Si}$ $0.51 \%$, Fe 1.26\%, Cu 0.35\%, Mn 0.27\%.

The percentage dilution method was used to dilute the distillery wastewater sample with distilled water. After reviewing the literature to analyse distillery wastewater samples, the $50 \%$ dilution was considered to investigate physicochemical parameters further. Also, many physicochemical parameters were found to have changed as a result. As a result, Table 1 lists the results of the distillery wastewater analysis. Therefore, the strength or concentration of the collected distillery wastewater sample was reduced after dilution, as were different parameters such as COD, TDS, TVC, Chlorides, Sulphate, Magnesium, Hardness, and Calcium content (see table 1). Only after dilution of a concentrated sample could the physicochemical characteristics of distillery wastewater be determined; thus, diluting the samples was necessary to determine the exact concentration of the pollutant in treated wastewater.

In table 1 , the dilution technique does not reduce distillery parameters on a large scale. As a result, dilution is not an effective way to reduce the parameters of distillery effluent. Worldwide, the distillery industry is the most polluting, and dilution is not an option because the effluent generated from ethanol, alcohol, and rectified spirit is around $15-16$ litres.

Table 1. Values of concentrated and diluted distillery wastewater samples.

\begin{tabular}{lrr}
\hline $\begin{array}{l}\text { Parameters in }(\mathrm{mg} / \mathrm{l}), \\
\text { except } \mathrm{pH}\end{array}$ & \multicolumn{1}{c}{$\begin{array}{l}\text { Initial } \\
\text { Value }\end{array}$} & \multicolumn{2}{c}{$\begin{array}{c}\text { Values after } 50 \% \\
\text { dilution of the } \\
\text { sample }\end{array}$} \\
\hline $\mathrm{pH}$ & 3.45 & 4.95 \\
$\begin{array}{l}\text { Chemical Oxygen } \\
\text { Demand (COD) }\end{array}$ & 115,271 & 100,584 \\
$\begin{array}{l}\text { Total Dissolved } \\
\text { Solids (TDS) }\end{array}$ & 92,587 & 83,651 \\
Total Suspended & 14,658 & 12,955 \\
Solids (TSS) & 7,921 & 6,547 \\
Sulphate & 8,115 & 6,815 \\
Chloride & 2,760 & 1,945 \\
Hardness & 2,498 & 2,157 \\
Calcium & 1,289 & 667 \\
Magnesium & & \\
\hline
\end{tabular}

The on-site anaerobic method has been carried out to minimise the parameters of the distillery spent wash. Methane (biogas) gas was generated during the biomethanation process, and the same has been utilised for the boiler. COD and BOD values were degraded to this anaerobic process around $65-75 \%$ and $80-85 \%$, respectively. So anaerobic treatment was the primary treatment accepted by the world to treat the distillery spent wash. Distillery spent wash required further posttreatment to degrade the parameter and safe disposal on the ground [13-15].

Distillery industries treat distillery spend wash by two fundamental methods: an anaerobic method (biomethane) and aerobic treatment followed by the anaerobic method. The aerobic way is effective to some extent, but the surrounding area is highly contaminated. As a result, new advanced technology is needed to deal with the cumbersome, complex, and recalcitrant melanoidin pigment. The distillery spent wash has undergone EC treatment to degrade the parameters.

\subsection{Electrocoagulation process}

Electro-coagulation is a simple, eco-friendly, advanced treatment technology. Process different modes of electrode connections in EC cells, such as the monopolar parallel (MP-P) method, monopolar series (MP-S), bipolar parallel (BP-P), bipolar series (BP-S), and batch mode operations to improve the efficiency of the EC. BP-S mode has an advantage over other methods, such as MP-S and BP-P, because BP-P measures the potential difference between the amplified electrodes, whereas several input electrodes form the MP-P output signal.

Two monopolar electrodes are connected in a parallel configuration in this mode, as shown in Figure 1. When compared to other types of connections, this one produces more output.

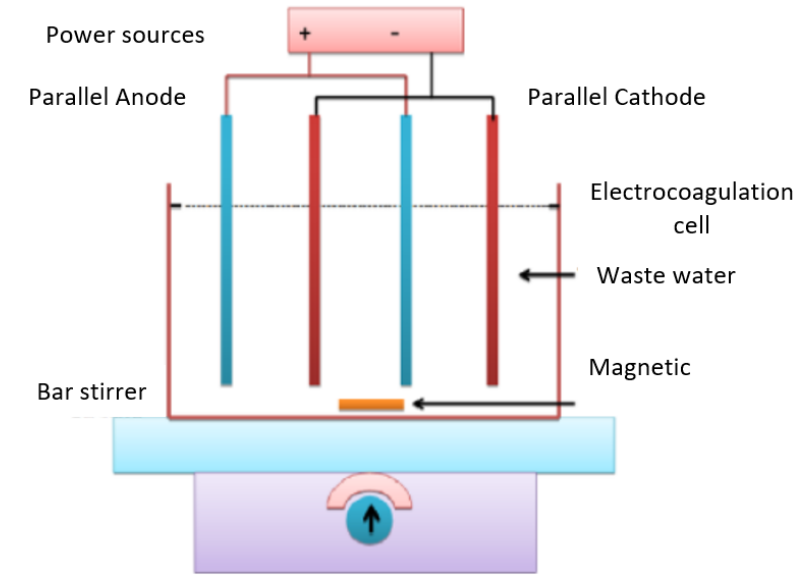

Figure 1. MP-P connection in EC process. 
The arrangements of the anode electrode and cathode electrodes are connected in a series manner (Figure 2)

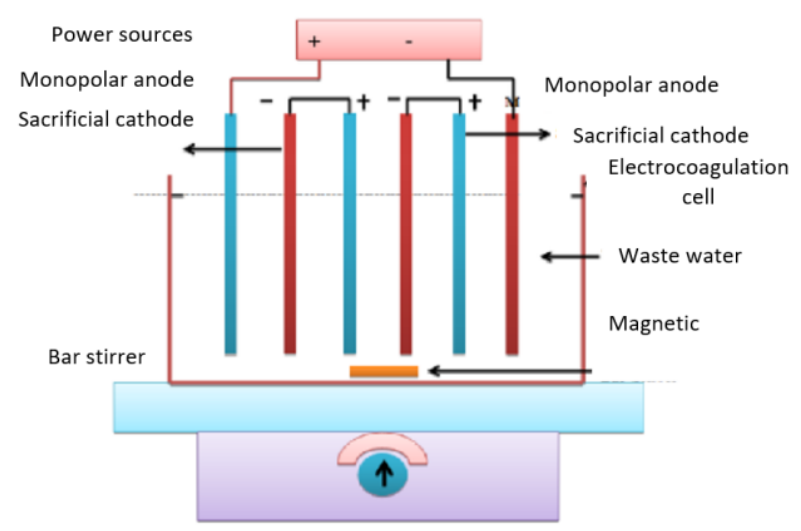

Figure 2. MP-S connection in EC process.

\subsection{Experimental Setup}

Figure 3 shows an experimental setup of a monopolar parallel (MP-P) electrode. The EC cell was made of acrylic glass to investigate how in situ coagulant doses applied to distillery spent wash and electron transition could be thoroughly investigated. The transparent medium allows proper mixing of the in-situ coagulant dose with the distillery wastewater. An impermeable glass membrane divides the EC cell into two parts, intending to separate the flock accumulated on the surface of the treated water. Because the flock floats on the surface, it could easily be separated from the treated water's surface. 1.5 litres could be stored in an EC cell.

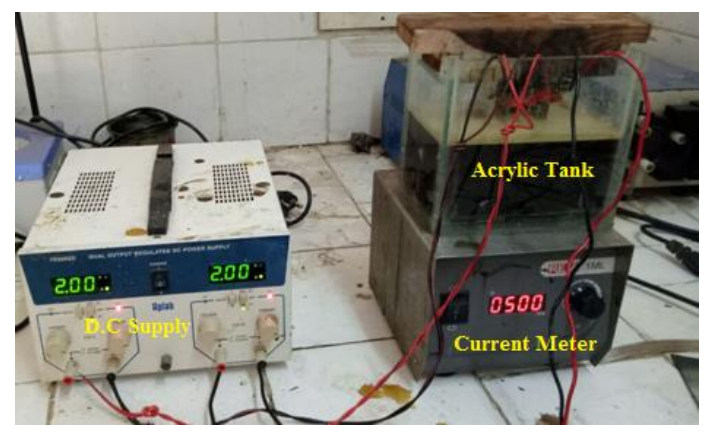

Figure 3. Actual experimental setup of monopolar parallel (MP-P) electrode.

The electrode for the experiment was a thin aluminium sheet with a purity of less than $97 \%$ and a thickness of $3 \mathrm{~mm}$. Cutting the aluminium sheet to the desired shape and dimension was accomplished. The aluminium sheet was sourced locally in Bagalkot, Karnataka. The most important consideration when deciding on the electrode condition was to achieve maximum submergence of the plate to apply an optimal dose of in situ coagulants. As a result, the electrode was 15 $\mathrm{cm}$ long, $10 \mathrm{~cm}$ wide, and $10 \mathrm{~cm}$ high. Aluminium foil (used for packing food) scraps were collected and cleaned with soap and tap water to remove dust, dirt, or grease. A uniform-sized of $1.5 \mathrm{~cm} \times 0.5 \mathrm{~cm}$ metal bits was preferred and selected for easy handling and uniformity. These metal scraps were used as fillings in packed electrodes. Before each experiment, the electrodes and packing materials were thoroughly cleaned with $15 \% \mathrm{HCl}$ and then rinsed with distilled water. The contact area of a single electrode was $12.5 \mathrm{~cm}^{2}$, or $5 \mathrm{~cm} \times 2.5 \mathrm{~cm}$; thus, the total size of the four electrodes used in the arrangement was $100 \mathrm{~cm}^{2}$, and the whole contact area was $100 \mathrm{~cm}^{2}$. The APHA standard procedure was followed to determine the colour, $\mathrm{pH}$, turbidity, and total suspended solids [16].

\section{RESULTS AND DISCUSSION}

\subsection{COD removal efficiency}

As in Figure 4, the effects of changing the voltage for different $\mathrm{pH}$ values on COD removal efficiency in percentage were obtained. The optimum COD removal was obtained for $\mathrm{pH}$ three and 120 minutes. The maximum COD removal is $77.29 \%$, and chemical oxygen demand degrades from $3850 \mathrm{mg} /$ litres to 874.335 $\mathrm{mg} /$ litres. This finding is consistent with the study carried out by [17]. Acidic $\mathrm{pH}$ has a more significant impact on COD removal. This is because some hydroxide ions are less in solution for acidic $\mathrm{pH}$, and chlorine/hypochlorite production decreases at higher $\mathrm{pH}$ conditions, as found by [18].

Besides, the in-situ aluminium coagulant dose is higher at a higher voltage for a more extended period, indicating that the electron of $\mathrm{Al}^{3+}$ has reached its saturation stage. As a result, an optimum coagulant dose yields higher pollutant species and COD removal efficiency, whereas a maximum quantity of coagulant results in decreased removal efficiency after the saturation level. The increased efficiency of removal is a function of current density, and the Faradays law causes the anode dissolution to increase.

Furthermore, as the voltage increases, the potential for hypochlorite production rises, resulting in increased hypochlorite production at higher voltages. COD removal rate increases with time until it reaches optimum condition, after which it decreases. The COD of the sample's initial and final concentrations after treatment is used to determine the efficiency of the EC process. The following equation was applied to calculate COD removal efficiency.

$C_{R}(\%)=\left(C_{i}-C_{f}\right) / C_{i} \times 100$

$\mathrm{Ci}$ and $\mathrm{Cf}$ are the sample's initial and final COD in $\mathrm{mg} / \mathrm{L}$, respectively, and CR is the COD removal efficiency. 
Colour removal efficiency is reduced on a large scale when the distillery spent wash is highly acidic ( $\mathrm{pH}-3)$. This is why distillery spent wash is complex, cumbersome, and intensive pollution as COD removal is effective for acidic $\mathrm{pH}$ and colour removal, and alkaline $\mathrm{pH}$ is appropriate.

The cathode electrode is passivated after a long process, another major factor affecting removal efficiency. As the process progressed, heterogeneous electrons in the electrolyte were attracted to the cathode, and thus the adhesion of such species increased with time. A thick layer of such material stops the electron transition from anode to cathode, reducing the overall process speed and allowing excess electron mobility. The electron coagulation process is hampered by passivity, which acts as a barrier. However, it is advisable to minimise the passivity of the electrode by applying various measures to remove the layer of adhesion material from the cathode. The maximum COD removal is $75.29 \%$ at $\mathrm{pH}$ 5, as in Figure 4(b).

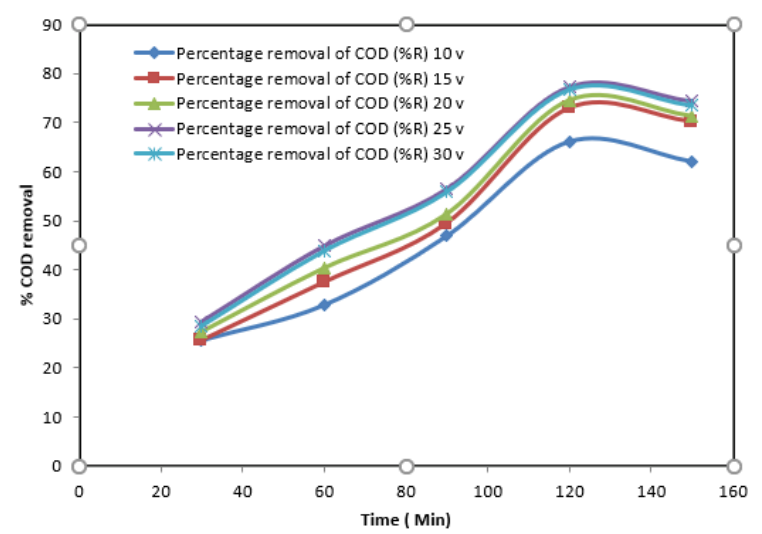

(a) $\mathrm{pH} 3$

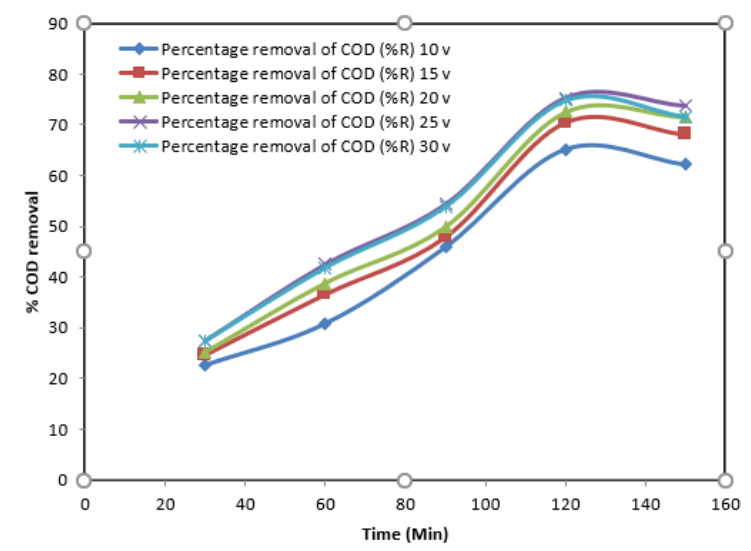

(b) $\mathrm{pH} 5$

Figure 4. The COD removal efficiency in MP-P connection.

The electrocoagulation process is investigated by varying the initial $\mathrm{pH}$ of the solution to see how $\mathrm{pH}$ affects the electrolysis time and current density. The same results are obtained for $\mathrm{pH} 3$, which is acidic, and $\mathrm{pH}$, which is alkaline. To get the desired $\mathrm{pH}$, add $\mathrm{NaOH}$ or $\mathrm{H}_{2} \mathrm{SO}_{4}$ to the solution. Because of the evolution of hydrogen bubbles at the cathode and subsequent reaction with anions such as $\mathrm{Cl}, \mathrm{HCO}_{3}, \mathrm{NO}_{3}$, and others, the results obtained for acidic $\mathrm{pH}$ solution show greater COD removal efficiency. Furthermore, some of the $\mathrm{OH}$ ions from $\mathrm{Al}(\mathrm{OH})_{3}$ are replaced by these anions, resulting in a significant increase in $\mathrm{pH}$. Maximum COD removal is $57.30 \%$ at $\mathrm{pH} 8$.

The EC process gives greater removal efficiency than alkaline $\mathrm{pH}$ at the lower initial $\mathrm{pH}$ of the distillery solution. Another reason behind the increase in the removal efficiency of distillery solution at lower $\mathrm{pH}$ values than higher is the formation of hypochlorite at higher current density. On the other hand, the analysis of results obtained for initial value $\mathrm{pH}$ of 8 gives another inference that the alkaline solution reduces the COD removal efficiency and hence it is due to the formation of hypochlorite formation. Therefore, the EC cell rate depends on the mobility of ions and electrode passivity.

\subsection{Colour removal efficiency}

Figure 5 gives the colour removal efficiency in the MP-P connection. The colour removal efficiency decreases on a large scale. This is why distillery spent wash is complex, cumbersome, and intensive pollution as COD removal is effective for acidic $\mathrm{pH}$ and colour removal, and alkaline $\mathrm{pH}$ is appropriate. The maximum colour removal efficiency is $57.19 \%$ at $\mathrm{pH} 3$, as in Figure 5(a).

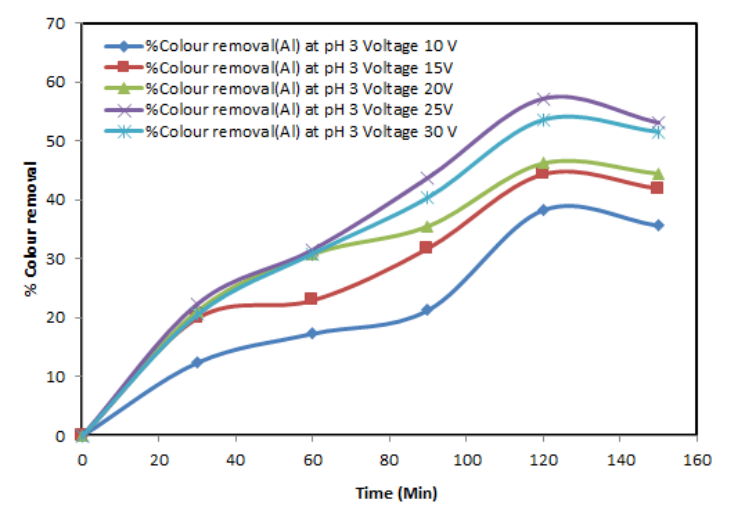

(a) $\mathrm{pH} 3$

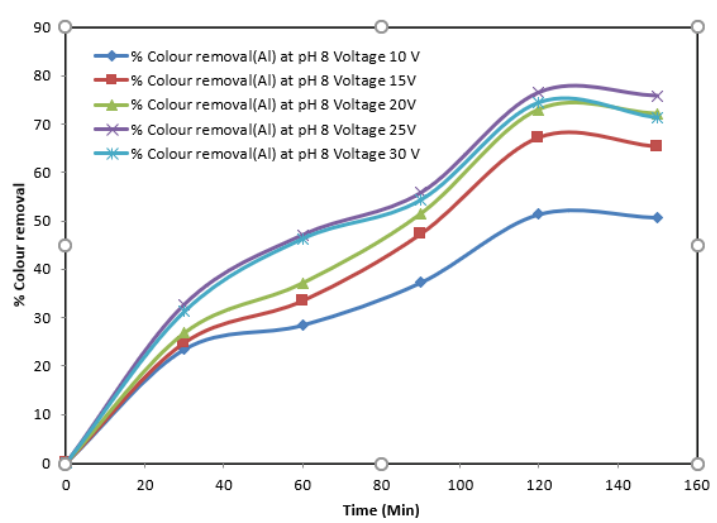

(b) $\mathrm{pH} 8$

Figure 5. The colour removal efficiency in MP-P connection. 
The colour removal efficiency is more when the effluent's $\mathrm{pH}$ is alkaline because the alkaline condition is more suitable for removing the colour of the pigment. Maximum decolourisation was obtained at $76.55 \%$ for pH 8 and time 120 min, as in Figure 5(b).

\subsection{Effect of $\mathrm{pH}$ on anode electrode (Scarifies electrode)}

Because of the increasing acidic $\mathrm{pH}$ oxidation rate, the metal oxide formation rate increases as the $\mathrm{pH}$ rises. The initial weight of the aluminium electrode during the EC process is $15 \mathrm{gm}$, which is reduced to $9,827 \mathrm{gm}$ after the EC process. The oxidation of the anode electrode causes anodic dissolution, as shown in Figure 6. The anode electrode's total consumption is around $34.48 \%$.

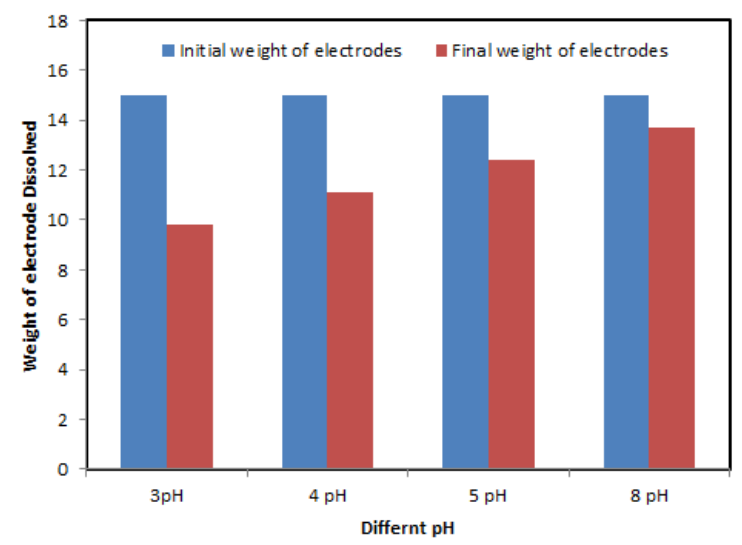

Figure 6. Change in weight of anode electrode in MP$P$ connection.

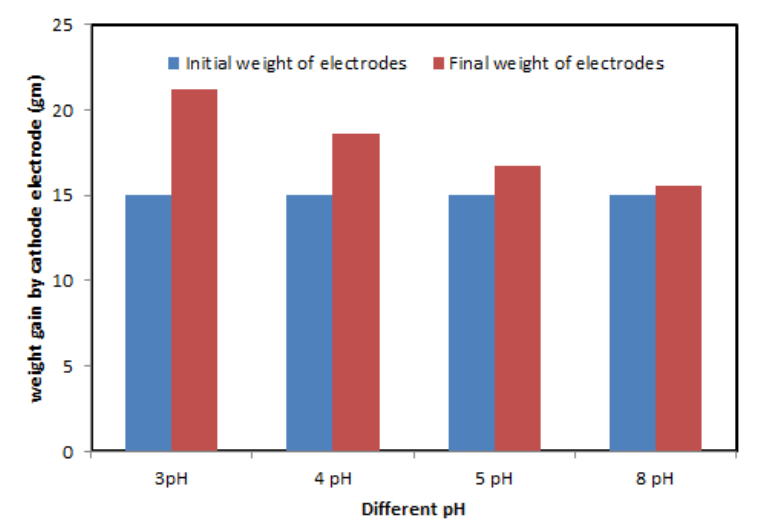

Figure 7. Weight gain by cathode electrode in MP-P connection.

\subsection{Effect of $\mathrm{pH}$ on the cathode electrode}

The weight of the anode electrode is deposited on the cathode electrode during the EC process, increasing the importance of the cathode electrode. As a result, the electrode loses weight while another cathode electrode gains weight. The cathode electrode gains about $6.2 \mathrm{gm}$ in total weight, including scum and sludge (Figure 7).
Because dissolved metal oxide reacts with organic and inorganic impurities in the distillery spent wash, it converts to floc and deposits on the cathode electrode. The total increase in weight is approximately $40.66 \%$, which is higher than dissolution [12].

\subsection{Effect of voltage on electrodes}

Electrode dissolution is directly proportional to the voltage applied. As voltage increases, the electrode dissolution rate also increases and vice versa (see Fig. 8). Weight dissolution is directly proportional to hydraulic retention time.

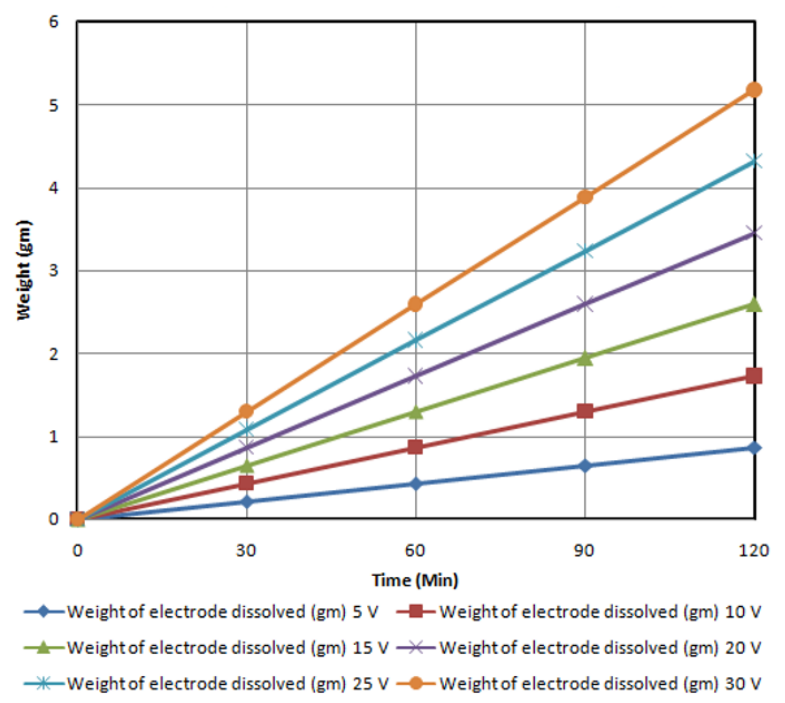

Figure 8. Weight dissolution of cathode electrode during EC process.

\subsection{Effect of $\mathrm{pH}$ on turbidity removal}

The turbidity removal rate increases with an increase in the duration of the process up to a certain level, and then it gradually reduces the reason that more metal oxide is dissolved in the distillery effluent during the EC process. During acidic $\mathrm{pH}$, more turbidity is removed. Figure 9 illustrates the turbidity removal at different $\mathrm{pH}$.

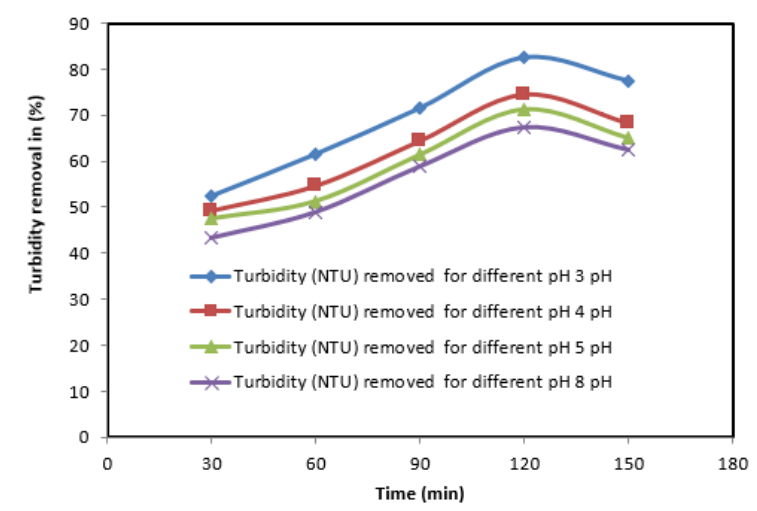

Figure 9. Turbidity removal at different $\mathrm{pH}$. 


\subsection{COD and colour removal by MP-S connection}

Decolourization of the distillery spent wash was carried out by implementing the EC process in the MP-S connection of electrodes. Figure 10 illustrates the relationship between the colour, $\mathrm{pH}$, and voltage at three varying $\mathrm{pH}$. A maximum decolourisation was achieved at $47.39 \%$ at $\mathrm{pH} 5$ and voltage $25 \mathrm{~V}$. An optimum colour removal was $45.39 \%$ at $\mathrm{pH} 3$, while a maximum colour removal was recorded at $61.35 \%$ at $\mathrm{pH} 8$.

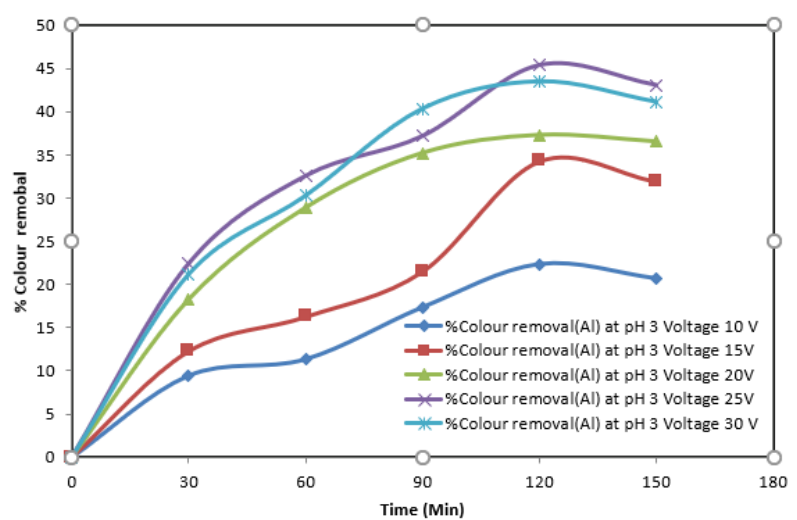

(a) $\mathrm{pH} 3$

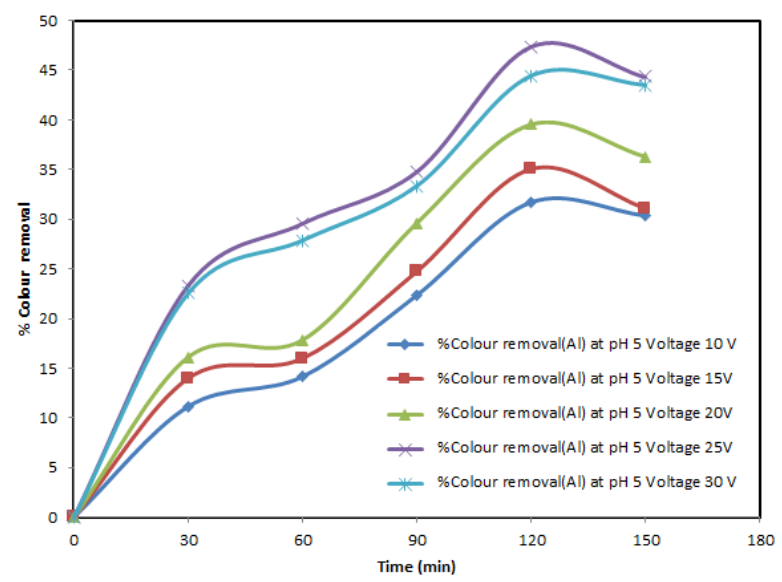

(b) $\mathrm{pH} 5$

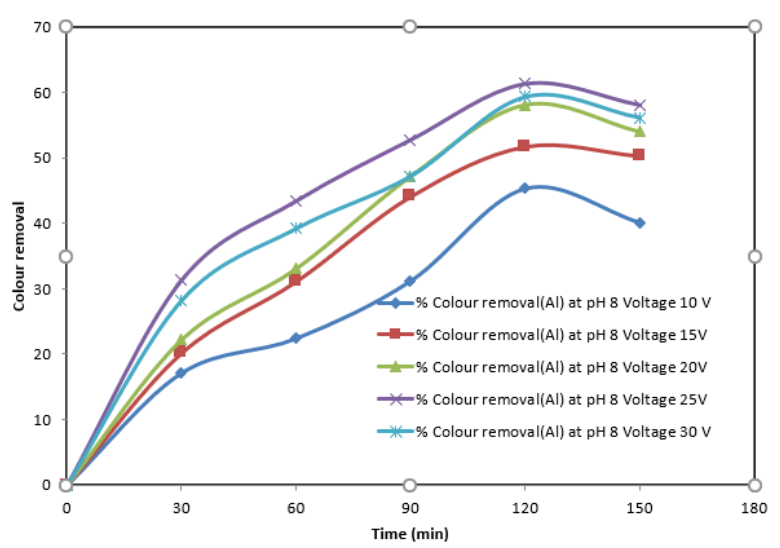

(c) $\mathrm{pH} 8$

Figure 10. Colour removal in MP-S.
Similarly, maximum COD removal achieved up to $68.12 \%$ at $\mathrm{pH} 5$ and voltage $25 \mathrm{~V}$. Figure 11 explains the relationship between the COD and the duration of the EC process, and the comparison is in table 2 .

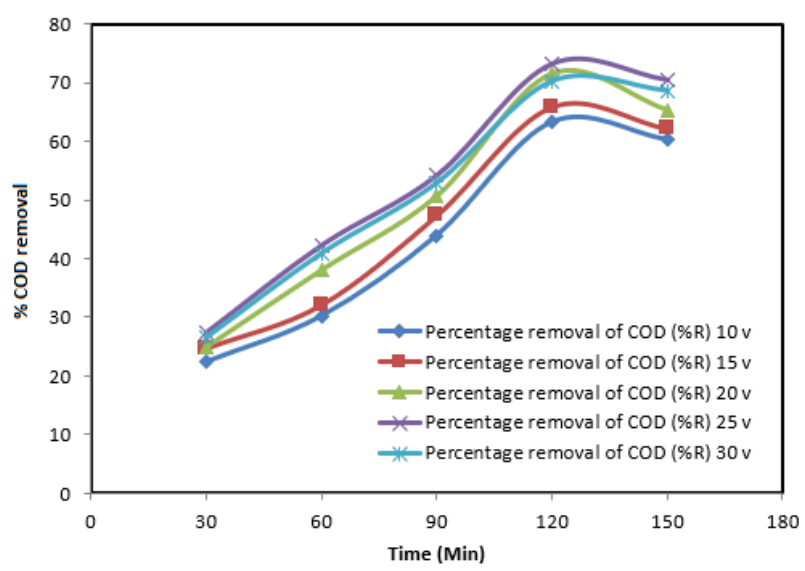

(a) $\mathrm{pH} 3$

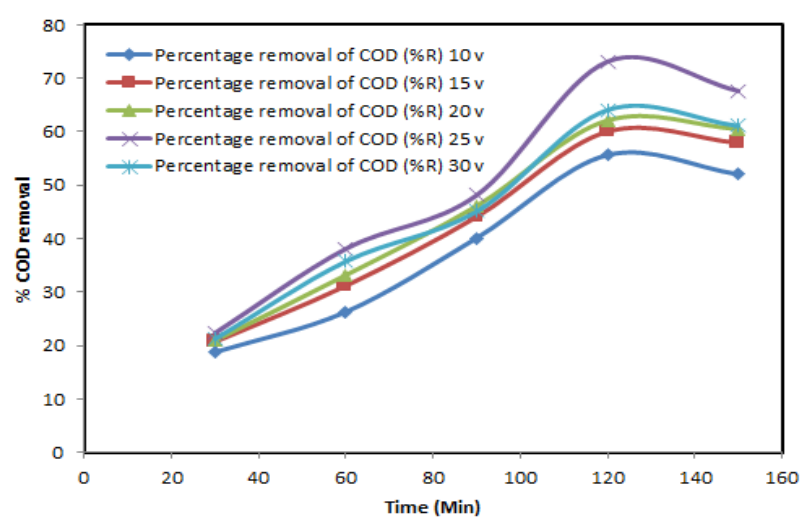

(b) $\mathrm{pH} 5$

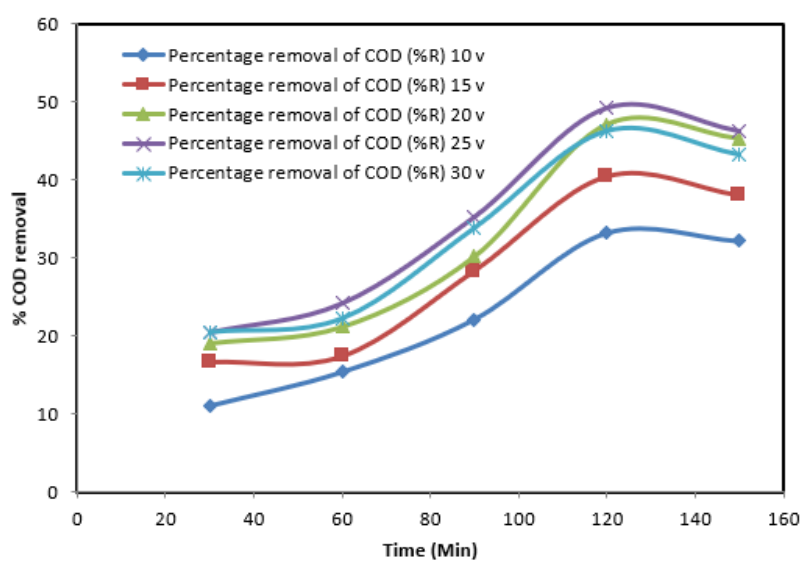

(c) $\mathrm{pH} 8$

Figure 11. COD removal in MP-S.

\subsection{Effect of $\mathrm{pH}$ and time on total solids (TS) removal}

Figure 12 displays the turbidity removal at various $\mathrm{pH}$ ranges from 3 to 8 . The acidic condition is suitable for removing the total solids in the distillery spent wash. The TDS of distillery effluent is significantly reduced by 64.72 
$\%$ by the electrocoagulation process concerning the time. When the effluent's $\mathrm{pH}$ is five, the voltage is $25 \mathrm{~V}$. Optimum TS is removed around $58.28 \%$. At the $\mathrm{pH}$ range of around eight and voltage of 25 , it is found that total TS removal is $42.44 \%$.

During the electrocoagulation process, the dissolved solids react with the $\mathrm{Al} 3+$ ions to form a gelatinous coagulant, destabilising the dissolved solids in the distillery wastewater, and thus, such partials can easily float, and hence they are caught by flock formed. The dissolved aluminium metal's free ions coagulate. Simultaneously, the cathode generates a hydrogen bubble, which floats dissolved solids and freely suspended ions of heterogeneous charge, reducing pollutant species suspended and colloidal molecules. After analysing the results, it was discovered that electrocoagulation effectively removes total dissolved solids.

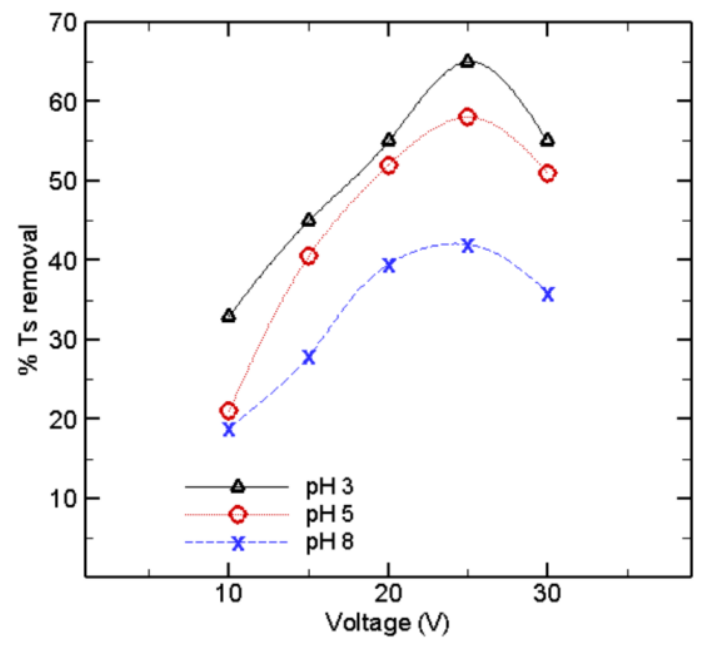

Figure 12. Turbidity removal.

\subsection{EC process for TDS, Sulphate and Chloride removal efficiency}

Particle destabilisation and accumulation are two steps in the electrocoagulation process. As a result, the dissolved solid reacts with the $\mathrm{Al}_{3}+$ ions during the $\mathrm{EC}$ process, forming a gelatinous coagulant that destabilises the dissolved solids in the DSW and accumulates the destabilised particle. As a result, such a practice can float effortlessly, creating a flock. The dissolved aluminium metal ions coagulate into free ions.

Simultaneously, the cathode generates a hydrogen bubble, which floats dissolved solids and freely suspended ions of heterogeneous charge, resulting in reduced pollutant species suspended and colloidal molecules. After analysing the data, it was discovered that the electrocoagulation method effectively removes total dissolved solids. The percentage removal of total dissolved solids, sulphate and chloride present in DSW is shown in Figure 13. TDS removal was $58.32 \%$, sulphate removal was $64.72 \%$, and chloride removal was $20.44 \%$, respectively.

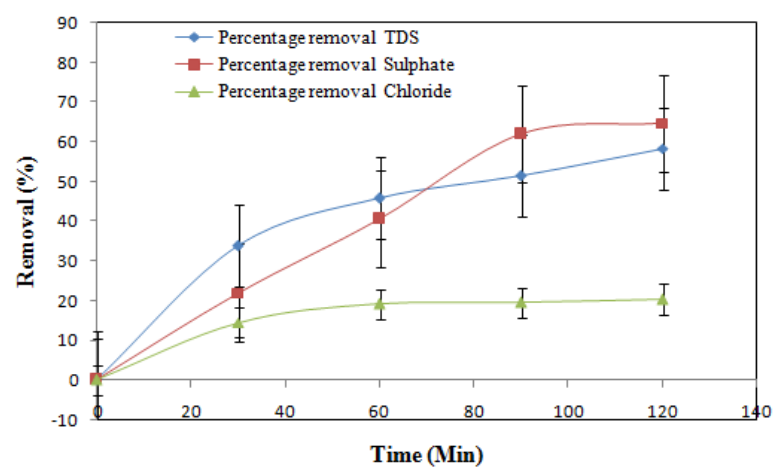

Figure 13. Removal of TDS, Sulphate, and Chloride.

\subsection{MP-P versus MP-S connection}

The efficiency of both methods has been carried out, and it found that the MP-P connection raises the removal rate of COD and decolourisation. These findings are similar to other research [19-22]. MP-P connection is simple and effective as output removal efficiency is more. The MP-S link measures the potential difference between the amplified pair of electrodes, whereas the MP-P relationship measures the potential difference between several input electrodes, resulting in a high removal rate.

Table 2. The comparison between MP-P and MP-S.

\begin{tabular}{cccc}
\hline Sr. No & Parameters & MP-P & MP-S \\
\hline 1 & COD removal for pH 3 & 77.29 & 73.13 \\
2 & COD removal for pH 5 & 75.29 & 68.12 \\
3 & COD removal for pH 8 & 57.30 & 49.24 \\
4 & Colour removal for pH 3 & 57.19 & 45.39 \\
5 & Colour removal for pH 5 & 59.09 & 47.39 \\
6 & Colour removal for pH 8 & 76.55 & 61.35 \\
\hline
\end{tabular}

\section{CONCLUSION}

The degradation of the former refining wash using the parallel monopolar and monopolar series electrocoagulation processes has been investigated experimentally. It can be concluded that the electrocoagulation technique could be employed to treat distillery wastewater. The COD removal efficiency is increased by increasing the current density range from 10$30 \mathrm{~V}$. An optimum COD removal is $77.29 \%$, and the maximum TDS removed is $58.32 \%$. The sulphate and 
chloride removal peak is $64.72 \%$ and $20.44 \%$, respectively. Electrocoagulation depends on two major physical parameters, such as the voltage and $\mathrm{pH}$ of the solution. The COD removal efficiency yields higher for the distillery spent wash's acidic $\mathrm{pH}$ solution. Hence, the electrocoagulation technique is best suitable for removing COD, Colour, TS, and turbidity from distillery spent wash using a monopolar parallel (MP-P) connection by using aluminium plate electrodes in a batch electrocoagulation unit. EC has the potential to be the distinct economic and environmental choice for the treatment of effluent and other related water management issues. The electrocoagulation method can be improved using plate electrodes of different electrode materials, mainly Al or Ruthenium oxide-coated titanium electrodes. The above phases can also improve by taking the accurate measurement for bipolar electrode arrangements and a more submerged area of both electrodes.

\section{CONFLICTS OF INTEREST}

No conflict of interest affects this publication.

\section{ACKNOWLEDGEMENT}

The author would like to thank the College of Engineering Ahmednagar, Maharashtra, India, for supporting the research facilities.

\section{REFERENCES}

[1] M.P. Wagh, P.D. Nemade, and S.R. Dhasal, "Colour and COD removal of distillery spent wash by using electrocoagulation", International Journal of Engineering Research and General Science, Vol. 3, No. 3, pp.1159-1173, 2015

[2] J. Shadmehr, S.M. Mirsoleimani-azizi, and S. Zeinali, "Electrocoagulation process for propiconazole elimination from wastewater: experimental design for correlative modeling and optimisation", International Journal of Environmental Science and Technology, Vol. 16, pp. 5409-5420, 2019. https://doi.org/10.1007/s13762018-1891-8

[3] M.P. Wagh, P.D. Nemade, and P. Jadhav, "Continuous electrocoagulation process for the distillery spent wash using Al electrodes", Proceedings of the 2nd International Conference on Advanced Technologies for Societal Applications, Vol. 2, pp. 4149, 2019. https://doi.org/10.1007/978-3-030$16962-6 \_5$
[4] O. Sahu, B. Mazumdar, and P.K. Chaudhari, "Electrochemical treatment of sugar industry wastewater: process optimisation by response surface methodology", International Journal of Environmental Science and Technology, Vol.16, pp. 1527-1540, 2019. https://doi.org/10.1007/s13762$\underline{018-1765-0}$

[5] M.P. Wagh and P.D. Nemade, "Treatment of distillery spent wash by using chemical coagulation (CC) and electrocoagulation (EC)", American Journal of Environmental Protection, Vol. 3, pp.159163, 2015. https://doi.org/10.12691/env-3-5-1

[6] M.P. Wagh and P.D. Nemade, "An influence of experimental parameters in the treatment of anaerobically treated distillery spent wash by using ozone assisted electrocoagulation", Desalination and Water Treatment, Vol. 83, pp. 7-15, 2017. https://doi.org/10.5004/dwt.2017.21041

[7] M.P. Wagh, "Ozone assisted electrocoagulation and fungal treatment for distillery spent wash", Ph.D. Thesis, Pune University, Pune, India, 2019.

[8] M.P. Wagh and P. Nemade, "Remediation and decolourisation of distillery spent wash by using advanced oxidation processes - A Review", Indian Journal of Environtment Protection, Vol. 39, No. 7, pp. 651-658, 2019.

[9] Z.B. Gönder, G. Balcığlu, Y. Kaya and I. Vergili, "Treatment of carwash wastewater by electrocoagulation using $\mathrm{Ti}$ electrode: optimisation of the operating parameters ', International Journal of Environmental Science and Technology, Vol.16, pp. 8041-8052, 2019, https://doi.org/10.1007/s13762019-02413-4

[10] M.P. Wagh and P.D. Nemade, "Treatment processes and technologies for decolourisation and COD removal of distillery spent wash: a review", International Journal of Innovative Research in Advanced Engineering, Vol. 2, No. 7, pp. 30-40, 2015

[11] M.P. Wagh and P.D. Nemade, "Biodegradation of anaerobically treated distillery spent wash by Aspergillus species from a distillery effluent contaminated site", Desalination and Water Treatment, Vol. 104, pp. 234-240, 2018. https://doi.org/10.5004/dwt.2018.21838

[12] M.P. Wagh, N.M. Mulik, and P.D. Nemade, "Electro-Coagulation [EC] process to treat basic dye", International Journal of Development Research, Vol. 6, No. 5, pp. 7858-7862, 2016. 
[13] K. Ravindra, M.P. Wagh, and S.B. Thakare, "Post treatment to biomethanated distillery spent wash by using Chitosan Powder", International Journal for Science and Advance Research in Technology, Vol. 3, No. 6, pp. 866-869, 2017.

[14] K. Ravindra, M.P. Wagh, and S.B. Thakare. "Application of Chitosan powder to enhance the properties of distillery spent wash", International Journal of Engineering Research and General Science, Vol. 5, No. 3, pp. 249-257, 2017.

[15] M.P. Wagh, P.D. Nemade, and A. Sengupta, "Augmentation with ozone-assisted electrochemical degradation of distillery spent wash for the removal of color and chemical oxygen demand", International Journal of Environmental Science and Technology, Vol. 18, pp. 619-630, 2021. https://doi.org/10.1007/s13762-020-02837-3

[16] APHA (American Publication Health Association), "Standard methods for the examination of water and wastewater", The 20th edition, American Public Health Association Inc. New York, 2008.

[17] M.P. Wagh, P.D. Nemade, and A. Biradar. "Assessment of Coagulation process for the distillery spent wash using Alum polyelectrolyte and Fenton", Indian Journal of Environmental Protection, Vol. 40, No. 7, pp. 747-751, 2020.
[18] E.S. Shahida, S.H. Afzali, N. Talebbeydokhti, and M. Rastegar, "Dye removal and disinfection in one reactor by non-pulsed high voltage current using iron, aluminum and copper electrodes", Desalination and Water Treatment, Vol. 178, pp. 337-346, 2019.

[19] M.P. Wagh, P.D. Nemade, U.P. Naik, and A. Sengupta, "Enhancing color and chemical oxygen demand degradation in distillery spent wash by electrocoagulation and ozone assisted electrocoagulation", Desalination and Water Treatment, Vol. 197, pp. 213-223, 2020. https://doi.org/ 10.5004/dwt.2020.25997

[20] M.P. Wagh and P.D. Nemade, "Biogas generation from distillery spent wash by using an opur western biotechnology process: a case study", Desalination and Water Treatment, Vol. 118, pp. 241-248, 2018. https://doi.org/10.5004/dwt.2018.22404

[21] R. Danial, L.C. Abdullah, and S. Sobri, "Potential of copper electrodes in electrocoagulation process for glyphosate herbicide removal", MATEC Web of Conferences., Vol. 103, 06019, 2017.

[22] A.Y. Gören, M. Kobya, E. S1k, E. Demirbas, and M.S. Oncel, "Combined influence of some cations on arsenic removal by an air-injection EC reactor using aluminum ball electrodes", Desalination and Water Treatment, Vol. 178, pp. 240-253, 2020. https://doi.org/10.5004/dwt.2020.24957 